Island Studies Journal, Vol. 3, No. 1, 2008, pp. 73-96

\title{
Start-up Success in a Small Island State: A Study among Entrepreneurs in Malta
}

Leonie Baldacchino

University of Malta, Malta

leonie.baldacchino@um.edu.mt

Vincent Cassar

University of Malta, Malta

vcassar@onvol.net

\&

Albert Caruana

University of Malta, Malta

albert.caruana@um.edu.mt

\begin{abstract}
This study focuses on entrepreneurs in the small island state of Malta and investigates whether starting up and running an enterprise is facilitated or hindered by being in a small island environment. Specifically it asks (1) whether being on a small island, on the periphery of a major market, facilitates or hinders entrepreneurship and start-up success; (2) whether Malta's cultural context and enterprise environment affect entrepreneurship and start-up success; (3) what the key success factors among Maltese start-ups are; and (4) how creativity and innovation are reflected in Maltese start-ups. Qualitative research among 13 start-ups is supported by telephone-based research among a sample of 90 respondents. Findings contribute to the pool of business expertise and context-specific information from small island states that is often missing from the international literature.
\end{abstract}

Keywords: creativity, innovation, entrepreneurship, start-up success, SMEs, Malta

(C) 2008 - Institute of Island Studies, University of Prince Edward Island, Canada.

\section{Introduction}

Small island states have been the subject of a great deal of research over the past few years. Some authors have emphasised their limitations and vulnerabilities (e.g. Baldacchino, 2002; Briguglio \& Kisanga, 2004) while others have focused on the impressive economic growth of various small island states which have outperformed many of the larger countries (e.g. Mehmet \& Tahiroglu, 2002). What most authors agree upon is that small island states are intrinsically different from larger states, not only in terms of their physical features, but also in terms of their social, economic and cultural context which together make up a particular micro environment (Baldacchino, 1995; Sultana, 2006). 
Starting up an enterprise is said to be the "hallmark of entrepreneurship" (Sternberg \& Wennekers, 2005: 193), yet it is reported to be highly susceptible to contextual factors (Dana, 2006). Consequently, successful new venture creation has been the focus of numerous studies in recent years that have sought to identify the various key success factors (e.g., Gilmore et al., 2004; Helms \& Renfrow, 1994; Lussier \& Pfeifer, 2001; Moy \& Luk, 2003; Peña, 2002; Schutjens \& Wever, 2000; Watson et al., 1998). However most of these studies have been carried out in larger countries and markets with the possibility that their findings may not be applicable to the particular circumstances of small island states. The micro environment of small island states is said to give rise to distinct business conditions that may influence entrepreneurship and start-up success.

This study focuses on entrepreneurs in Malta and investigates whether, in their opinion, starting up and running an enterprise is facilitated or hindered by being in a small island environment. Specifically it asks (1) whether being on a small island, on the periphery of a major market, facilitates or hinders entrepreneurship and start-up success; (2) whether Malta's cultural context and enterprise environment affect entrepreneurship and start-up success; (3) what the key success factors among Maltese start-ups are; and (4) how creativity and innovation are reflected in Maltese start-ups. Qualitative research among 13 start-ups is first conducted and subsequently supported by quantitative telephone research among a sample of 90 respondents. Results are reported and conclusions are provided. Findings contribute to the pool of business expertise and context-specific information from small island states that is often missing from the international literature. Limitations are noted and directions for future research are indicated.

\section{Malta: A Small Island State on the Periphery of the European Market}

Malta gained its political independence from Britain in 1964. It is a small island state with a total land area of $316 \mathrm{~km}^{2}$ and a population of just over 400,000 . It is located $93 \mathrm{~km}$ south of Sicily in the heart of the Mediterranean. The sea acts as a natural barrier that delineates Malta from the rest of the world. Not surprisingly these characteristics give rise to its peripheral nature. Despite European Union (EU) membership in May 2004, travel and transportation costs are higher, making integration that much more challenging. Malta has no exportable natural resources and the manufacturing industry needs to import the bulk of its raw material requirements. A small domestic market makes Malta's economy dependent on exports for growth. It has been argued that small states can find ways to overcome or compensate for such difficulties (Baldacchino, 1999). Proof of this is the exceptionally high per capita income levels of microstates such as Luxembourg, Bermuda, Singapore, Hong Kong and Brunei. These can be attributed to certain unique characteristics - such as location and climate - that can provide small states with an economic advantage in sectors such as tourism and financial services (Mehmet \& Tahiroglu, 2002). Despite the fact that its location and climate are indeed favourable for at least two of its main economic pillars - financial services and tourism - Malta does not rank with the top countries in terms of European and global competitiveness (World Economic Forum, 2006a; 2006b). Moreover, start-ups in small island states like Malta often face a double dose of vulnerability. They are exposed to both the start up challenges 
of their local environment and in addition they are highly susceptible to shocks arising from the global economy. On the basis of the above, we ask:

RQ [Research Question] 1: Does being on a small island, on the periphery of a major market, facilitate or hinder entrepreneurship and start-up success?

\section{The Socio Cultural and Enterprise Environment}

Malta, as a small island state on the periphery of the European market, has its own particular identity and socio-cultural context that influences how business is undertaken and how entrepreneurship and start-ups are facilitated or hindered. This section looks at a number of socio-cultural variables and the enterprise environment that characterise Malta.

\section{Openness to New Ideas}

It has been argued that "countries without natural resources are much more likely, through human evolution, to develop the habits of openness to new ideas, because it is the only way they can survive and advance" (Friedman, 2005: 328). In this view, citizens of small island states would be expected to generate and accept new ideas to compensate for a lack of natural resources and to overcome the other drawbacks of living and operating on a small island. Maltese entrepreneurs report a broad continuum of views concerning Malta's openness to new ideas which range from concurrence that locals have a "creativity spirit" which comes from the need "... to survive on a rock without any natural resources" to outright disagreement where locals are said to be "sceptical to investing in new ideas" (Mercieca \& Cassar, 2006: 9). Malta's receptivity to new ideas remains an open question that requires further investigation.

\section{Reputation and Fear of Failure}

Malta's small size and high population density makes it seem as though everyone knows everybody else with limitations on anonymity and privacy. Failure, like success, is easily visible and becomes widely known. Unlike larger states, citizens cannot achieve anonymity from any type of failure simply by relocating to another part of their home country. In addition, an individual's reputation is closely linked to a strong sense of family honour, pride and shame. Despite many changes since the 1960s, Malta in 1992 was reported to exhibit very much the same characteristics of "... loyalty to family, faction and community" (Boissevain, 1993: 160-161). There is no reason to argue that these have changed since either. Such values have important implications for new entrepreneurial undertakings and start-up success: generating and implementing innovative ideas involves inherent risks and a high possibility of failure (Gilmore et al., 2004; Kuczmarski, 1996). It is proposed that such a prevalence of fear of failure undermines entrepreneurial activity.

\section{Strong Family Values}

The presence of strong family values in Maltese culture could explain why the family "remains influential in shaping educational and occupational aspirations and paths" 
(Sultana, 2006: 40). Indeed it has been pointed out that "... small business is family business. Family and enterprise are intimately related" (Boissevain, 1991: 2). Mercieca and Cassar (2006) present evidence that family support, assistance and encouragement were deemed to be very important by Maltese entrepreneurs, and were sorely missed when absent. It is argued that a family's attitude toward starting up an enterprise, and the degree of support it offers, are likely to be determining factors of entrepreneurial activity and its success.

\section{Friends of Friends}

The importance of one's personal contacts and social networks, or one's "friends of friends" (Boissevain, 1974), is recognized as a key factor for success. "It's who you know, not what you know" (Sultana, 2006: 42) that opens up opportunities and helps you get ahead in a place like Malta. When studying innovation and networking in small manufacturing firms in Cyprus, Dickson and Hadjimanolis (1998) found that the ownermanagers' personal and social relationships positively influence their organizational relationships with new and existing customers, partners and suppliers. Overseas links were also found to be of critical importance for Cypriot firms that depend on foreign suppliers for raw materials, machinery, equipment, technical information, technology and expertise. Most business deals and opportunities rely on personal contacts to bring in new clients and reliable suppliers. In such a perspective, successful entrepreneurship depends to a large extent on the scale and quality of social networks.

\section{Familiarity may lead to Contempt}

In spite of the high level of familiarity in small states, local cooperation and collaboration is not necessarily easier. Familiarity may lead to disrespect and contempt (Sultana, 2006). Indeed, in Cypriot firms, relationships between local firms and their suppliers, customers and subcontractors are characterised by low trust, lack of commitment, unreliability and dissatisfaction (Dickson \& Hadjimanolis, 1998).

\section{The Enterprise Environment}

The open systems perspective holds that start-ups rely heavily on their environment for resources (Cummings, 2005a; 2005b). Opportunity, motivation and skill are three key ingredients for entrepreneurial success. Opportunity refers to the support environment in terms of available resources, regulatory environment and state administrative support. Enterprises started by skilled and/or motivated individuals in unsupportive, low opportunity environments are likely to experience more difficulties and barriers to entry than those started in supportive, high opportunity environments (Lundström \& Stevenson, 2005).

With the generous provision of European Union (EU) funds for seminars, conferences, training programmes, incentive schemes and other enterprise support, the Government of Malta has sought to promote entrepreneurship and innovation in recent years. Political declarations and the allocation of public funds point towards a top-down effort to create a 
positive environment for fostering innovation and enterprise. Yet the 2006 Lisbon Review reports that Malta is still lagging behind its European counterparts in terms of overall competitiveness, enterprise and innovation levels. Malta ranked $19^{\text {th }}$ out of the $25 \mathrm{EU}$ member states, with an average final index score of 4.38 out of a maximum possible score of 7.00, compared to Denmark's top ranking score of 5.76 and an EU average of 4.84 (World Economic Forum, 2006a). One of the dimensions measured in the Lisbon progress study was the enterprise environment with regards to start-ups and regulatory frameworks. This subscale measured factors such as the time required and red tape involved to start up an enterprise, the quality of legislation, taxation, and the level of capital available for new enterprises. Malta ranked $22^{\text {nd }}$ and scored a low 3.83 out of a maximum possible score of 7.00 on this index, compared to Denmark's top ranking of 5.63 and an EU average of 4.59 .

On a global scale, Malta's competitiveness and economic performance is equally disappointing. The 2006 Global Competitiveness Report placed Malta in $39^{\text {th }}$ place, with a final score of 4.54 out of a maximum possible score of 7.00, compared to Switzerland's top rank with a score of 5.81. Among the states that outperformed Malta are three other island states: Barbados, Singapore and Iceland (World Economic Forum, 2006b).

In summary, the context for start-ups in Malta may be described as rather challenging. The small size of the island, limited domestic market, peripheral location and other socio cultural variables are difficult hurdles that need to be overcome. Moreover, in spite of a declared government policy and various support measures aimed at boosting enterprise, Malta's low European and global rankings on competitiveness, enterprise and innovation levels suggest that Malta has not yet found a way to compensate for the handicaps imposed by its smallness and islandness. Our consideration of Malta's socio-cultural variables and enterprise environment lead us to ask:

RQ2: How does Malta's socio-cultural context and enterprise environment affect entrepreneurship and start-up success?

\section{Success Factors among Start-up Firms}

There is broad agreement that success and growth of small enterprises is determined by a web of factors (Lee \& Osteryoung, 2001; Simpson et al., 2004; Watson et al., 1999). Education, experience, preparation, hard work, motivation and commitment have been identified as desirable attributes of owner-managers of start-ups (Gilmore et al., 2004; Lussier \& Pfeifer, 2001; Peña, 2002; Schutjens \& Wever, 2000; Watson et al., 1998). Other factors such as size, structure, and economic activities have been associated with the start-up itself (Schutjens \& Wever, 2000). Most start-ups are generally small with only a few employees and an organic structure. Although this structure may denote vulnerability, it allows start-ups to be more flexible and agile. Flexibility is undoubtedly a key success factor for small enterprises, as their simplified management structure enables them to concentrate on short runs and switch procedures rapidly (Boissevain, 1991; Peña, 2002). In addition a number of other success factors have been noted in the literature. These include employing the right staff (Lussier \& Pfeifer, 2001), effective marketing strategies and 


\section{Baldacchino, V. Cassar \& A. Caruana}

location (Hill et al., 2002), the use of mentors or professional advice (Helms \& Renfrow, 1994; Lussier \& Pfeifer, 2001; Waters et al., 2002), and the use of advanced technology (Smallbone et al., 1995; McGrath \& Gilmore, 1995). There are also factors in the environment in which start-ups will be operating that may influence their success. A positive industry environment - which includes a stable and supportive political climate, fiscal regulation, infrastructure and labour markets - would favourably affect the evolution of successful start-ups (Peña, 2002). Dodge and Robbins (1992) found that financial challenges including undercapitalization and locating financial sources are predominant during an enterprise's earlier years. Capital is often the major problem that entrepreneurs must overcome during this period (Moy \& Luk, 2003; Peña, 2002). On the basis of the above, we ask:

RQ3: What are the key success factors among Maltese start-ups?

\section{Creativity and Innovation}

It has become widely accepted that no enterprise can flourish without a healthy dose of creativity and innovation. Creativity and innovation are considered to be overlapping constructs between two stages of the creative process; both are necessary for successful enterprise (Martins \& Terblanche, 2003). Creativity can be defined as "the production of novel and useful ideas" (Amabile et al., 1996: 1155), while innovation refers to the implementation or "transformation of a new idea into a new product or service, or an improvement in organization or process" (Heye, 2006: 253). By definition, creativity and innovation involve the creation of something new that "... is central to the entrepreneurial process" (Barringer \& Ireland, 2006: 15). Creativity and innovation are in fact considered by many to be inseparable from entrepreneurship, which is in turn manifested in the act of starting up and running an enterprise.

In organizational settings, creative ideas can be implemented to introduce innovative products or services, or to deliver products or services in a new, more efficient, and hence innovative way. There is broad agreement that innovation should be present in all aspects of an organization and that it should be a mindset or a way of life (Abraham \& Knight, 2001; Kuczmarski, 1996). Innovation should permeate through the various elements of the organization's business model in order to make it harder to be copied by competitors (Loewe \& Dominiquini, 2006). Therefore, innovation is not only measured by the new products or services offered by an enterprise but also by new and more efficient ways of developing, producing or delivering products or services.

It is argued that creativity is not required solely in the domain of certain sectors or departments, or only in the development of new products or services, but is needed at every level of every type of organization. Creativity is seen as going beyond new products, new services and new and improved processes (Cook, 1998; Heye, 2006). Therefore if one can "better organize [one's] day or write a report in a new or more effective way, then this is every bit a creative act" (Gurteen, 1998: 7). On the basis of the above, we ask: 
RQ4: How are creativity and innovation reflected in Maltese start-ups?

\section{Methodology}

This study makes use of mixed methods, with data collection taking place in two phases. Phase One utilises a qualitative method of data collection to address the first three research questions. Phase Two makes use of a quantitative method to substantiate the third research question and to answer the fourth. The data collected in Phase One is fully analysed before Phase Two is conducted, as the preliminary findings from the qualitative research are fed into the quantitative part of the study for further investigation.

For enterprises to be included in this study they needed to meet the "new" and "active" criteria as described by Luger and Koo (2005). Enterprises which were set up in Malta in the last five years were considered to satisfy the "new" criterion. There is likely to be no controversy with including young enterprises in the start-up category, but it may be argued that enterprises in their fifth year may be said to have grown out of their "new" start-up stage. However start up firms that have survived beyond the treacherous early years, and are in their fourth or fifth year, are able to offer valuable hindsight concerning factors leading to start-up success. This is in line with the suggestion by Bosma and Harding (2007) concerning the importance of studying both nascent entrepreneurs and those with more experience to gain insight into start-up success. A five-year time span was therefore deemed appropriate for this research. The "active" criterion was satisfied if the enterprise employed at least one full-time employee (excluding the owner-manager) and was engaged in some form of commercial activity.

\section{Phase One: Personal Interviews}

In Phase One, in-depth personal interviews were carried out with 13 owner-managers of new and active start-ups. Respondents were identified through the principal business incubation centre in Malta and through personal contacts. This first phase sought to provide insight into the phenomenon of starting up and running a successful enterprise in a small island state. In these circumstances, a qualitative approach was considered to be the most appropriate as it allowed in-depth exploration of the issues under investigation.

A tailor-made, semi-structured interview schedule that included the main questions, prompts and probes, was used to ensure coverage of key issues and to guide the interview process (Creswell, 1998). The interview schedule, which was also translated into Maltese, was rigorous enough to enable the identification of patterns and trends, but was sufficiently flexible to allow the interviewer to follow emergent leads (FrankfortNachmias \& Nachmias, 1996). Questions were open-ended and as non-leading and as unambiguous as possible. All interviews began with the respondents being asked to provide some details about themselves and their start-up. These opening questions were non-threatening ice-breakers to help put the respondents at ease, build rapport between the interviewer and the interviewee and at the same time provide a wealth of information about the owner-manager's background. Respondents were then asked an open, general question about what they felt were the major factors that contributed to the success of their 
start-ups. Probing questions, using the respondents' own words where possible, were used to invite the owner-managers to expand upon the points they had raised.

One objective of this research phase was to determine how Malta's small island state context, and its socio-cultural and enterprise environment influence start-up development and success. Respondents who did not spontaneously volunteer context-specific information were directly questioned on whether there was anything about Malta's small size, island nature and peripheral characteristics that they felt undermined or enhanced start-up success. Along similar lines, respondents were asked about the Maltese environment for enterprise in terms of state support and legislation for starting up an enterprise. The interview was concluded with a broad question that asked if respondents would like to add any further comments.

Interviews were conducted in the English or Maltese language, depending on respondent preference, and lasted around 45 minutes each. Gilmore et al. (2004) suggest that the understanding of entrepreneurial phenomena is enhanced when they are examined in their own natural context. Consequently, all interviews were carried out on the respondent's business site. Interviews were audio-recorded and transcribed in full to ensure accuracy and objectivity in data collection and to facilitate analysis. Notes on the respondents' nonverbal behaviour were also recorded in the space provided on the interview schedules, in order to take advantage of the richness of information provided by the personal nature of this method of data collection (Frankfort-Nachmias \& Nachmias, 1996). Prior to analysis, each transcript was e-mailed to the respective respondent for a process of membervalidation, whereby they were asked to read through the document and verify that the information was reported truthfully and accurately, and to make amendments if necessary.

\section{Phase Two: Survey Data}

In Phase Two, respondents were still required to meet Luger and Koo's (2005) "new" and "active" criteria. Selection of suitable research participants was carried out using purposive sampling (Shaughnessy \& Zechmeister, 1997) to ensure that all the research participants met the research criteria. This led to the creation of a theoretically relevant sample which is deemed most appropriate in entrepreneurial research (Davidsson, 2004). Since the second phase of this study was quantitative in nature, it required a larger research sample than the qualitative first phase. A sampling frame of "active" enterprises was compiled from the Made in Malta Business Directory and ICT Business Directory published by Malta Enterprise, and from the Trade Directory published by the Malta Chamber of Commerce. Since enterprises appearing on these directories were publicly advertising their products or services, it could be safely deduced that they were involved in commercial activity. This eliminated the selection of companies that may have been dormant or existed only as 'paper companies'. Each entry in these directories was looked up on the online Malta Registry of Companies to determine their registration number and their year of incorporation. Those companies registered during the last five years were considered to fit the "new" criterion and therefore included in this research sample, which also included the participants from the first phase of the research, other enterprises based at the local business incubation centre, and further personal contacts. The lengthy 
selection process yielded a sampling frame of 152 "new" and "active" enterprises. The entire sampling frame was contacted, out of which 90 owner-managers agreed to participate in the study. This response rate of $59.2 \%$ is attributed to the hectic schedule that is typical of many owner-managers of successful start-ups, which leaves them with little time to participate in research.

This second phase of data collection sought to investigate how creativity and innovation are reflected in Maltese start-ups and to further assess their key success factors. Since contextual differences needed to be taken into account in this study, and since research on creativity is typically carried out in large organizations, a tailor-made structured interview schedule was constructed for the purpose of this second phase of the study. The construction of this interview schedule was based on the main findings of Phase One and on a number of standardized instruments dealing with organizational creativity. These include Goodman's Organizational Creativity Audit (1995), Ekvall's Creative Climate Questionnaire (1987), the Harvard Business Essentials' Workplace Assessment Checklist and Psychological Environment Checklist (2003), and the Advanced Practical Thinking Training Inc.'s Innovation Index (2001).

The final interview schedule was divided into three parts. Part one gathered general information about the respondents and their start-ups, including the industry sector they form part of, the year when their enterprise was set up, the number of employees, and the owner-manager's previous managerial and start-up experience. The data gathered from this first part of the interview was later used to classify and profile respondents. Part two of the interview schedule addressed the fourth research question, which is concerned with how creativity and innovation are reflected in Maltese start-ups. Items in this section represent indicators of organizational creativity and innovation (product, service and process innovation), together with indicators of the psychological and physical environment of the start-ups under investigation. All the items in this part of the interview schedule were selected entirely on the basis of the literature reviewed and the instruments mentioned above. Replies required simple 'yes' or 'no' answers. The final part of the interview schedule substantiated the third research question, which was concerned with identifying what are perceived to be the key success factors behind start-ups in Malta. Since this study argues that creativity and innovation are central to Maltese start-up success, respondents were requested to weigh creativity and innovation against twelve other factors. All factors had been identified as key success factors in the literature and in Phase One of this research. Respondents were instructed to refer to their own start-up experience and to report which of the twelve factors had been of greater importance, which had been of lesser importance, and which had been of equal importance to creativity and innovation. An open-ended general question at the end of the interview allowed respondents to add any further comments and to suggest additional critical success factors.

The survey interviews in Phase Two were all administered over the telephone. This survey method was selected because of its non-intrusive nature, and because it was permitted by the relative simplicity of the research instrument (Frankfort-Nachmias \& Nachmias, 1996). Interviews were conducted in English or Maltese during office hours or at such 
times as requested by respondents, and lasted approximately six minutes each. Answers were recorded on the interview schedule sheets which were then used by the author for analysis.

\section{Results}

Out of the thirteen owner-managers who participated in the first phase of this study, four had started up their enterprise in 2002, two in 2003, five in 2005, and two in 2006. Ten respondents were male and three were female while two were foreign and eleven were of Maltese nationality. One respondent was aged 25 or under, five were aged between 26 and 35, five were aged between 36 and 45, and two were aged 46 or over. All respondents in Phase One had completed tertiary level of education. Nine respondents had no previous start-up experience but eleven had formerly been employed in managerial positions.

In Phase Two, telephone interviews were conducted with 90 owner-managers whose enterprise had been registered with the relevant authorities in the last five years. All startups in this research sample fell into the SME category as defined by the EU. Micro and small enterprises together made up $96.7 \%(n=87)$ of the sample. This is comparable to the population of enterprises in Malta, where micro and small enterprises together account for 99.3\% of all Maltese businesses (National Statistics Office, 2006a \& b). Out of the 90 respondents, $83.3 \%(n=75)$ were male and $16.7 \%(n=15)$ were female. When compared to the gender distribution of the population of self-employed with employees, females were over-represented in this sample. No data is publicly available on the gender distribution of new enterprise owners. Respondents with managerial experience constituted $81.1 \%(n=$ 73) of the sample, while those with experience starting up and running their own enterprise made up $38.9 \%(n=35)$ of the sample. In addition, enterprises forming part of the ICT sector were highly represented in this phase of the research, constituting $25.6 \%(n=23)$ of the sample. The start-ups with the second highest frequency in the sector variable were those which offer some kind of consultancy services, making up $8.9 \%(n=8)$ of the sample. This was followed by those in the financial services sector, of which there were $6.7 \%(n=6)$. Other sectors, including manufacturing, retail, import/export, hospitality, education and culture, media and entertainment, biotech, health, environment and energy were all represented by between one and four start-ups, making this a highly heterogeneous sample in terms of industry sector representation.

\section{RQ1: Does being on a small island, on the periphery of a major market, facilitate or hinder entrepreneurship and start-up success?}

The general consensus among the owner-managers who participated in the personal interviews was that local start-ups are affected to some extent by the conditions brought about by Malta's small island state context. Six of the thirteen respondents spontaneously made reference to these conditions and another six referred to them upon direct questioning. They disagreed, however, on whether such conditions are beneficial or detrimental to start-up success. Only one respondent felt that there was nothing about the small island state context of Malta that particularly affected him in his enterprising activities: 
No problem ... if you are in the knowledge industry you could be based anywhere: in Gozo, on a yacht...

Among the respondents who felt that Malta's small island state context facilitates matters for start-ups were the two foreigners. They sang praise for the ease with which they were able to make direct contact with the relevant Authorities during their start-up process. They consider this to be a facilitating factor for start-ups and believe it is only possible due to Malta's small size. This feature was also reported by a Maltese owner-manager in the financial services sector whose start-up involved attracting new investors from overseas to the island. He states:

Another thing which has really helped to sell Malta is that being a small island you're only literally a phone call away from the regulator ... whereas if you live [elsewhere] that's impossible to do because you have to talk to about eight people before you get to the regulator, and it takes a long time.

One of the foreigners claimed that due to its small size and receptiveness to new ideas, Malta is an ideal testing ground for new products and services which, if successful, could be launched on the larger international market.

Despite the above, the dominant view among respondents in the first phase of this study concerning Malta's small island context was somewhat negative. Two respondents referred to the sea as being a natural geographical barrier which held them back from expanding their business. Malta's small size was explicitly mentioned as being detrimental to start-up success by three respondents, as they felt it creates a limited domestic market and fierce competition.

\section{RQ2: How does Malta's socio-cultural context and enterprise environment affect entrepreneurship and start-up success?}

The first major socio-cultural theme that emerged in the personal interviews as being central to start-up success in Malta is family influence and support. Most of the ownermanagers who participated in Phase One of this study attribute a great deal of importance to their family or to their partners, both as influencers in their decision to start up and as sources of support during the start-up process. One respondent explained how both his father and his grandfather were entrepreneurs, and felt that this influenced his decision to start up his own enterprise, stating that "the family influence I think helps a lot in forming a person into business". In his case, he felt it was "something ... in the line, in the family". Another respondent claimed that starting up an enterprise was in his blood as he also came from a family of entrepreneurs.

The role of the owner-managers' spouses is also reportedly instrumental in the success of start-ups. A respondent explained how his fiancée encouraged him to start up on his own and constantly encourages him and supports him through the tough times. Another respondent believes that "if it weren't for them [wife and children] ... I wouldn't be here in the first place". This respondent explained that family support is so important because "in a 


\section{Baldacchino, V. Cassar \& A. Caruana}

start-up, a company like ours, you don't say you work 40 hours a week". Another respondent reported he relied on his wife for financial support when his start-up was going through some very rough patches.

The second major socio-cultural issue raised was the importance of personal contacts, networking and word of mouth, as "everyone knows someone in Malta, and everyone knows someone who knows someone". Closely related to this is the issue of reputation, which also emerged as being of utmost importance for start-up success in Malta. Seven owner-managers made reference to these interrelated concepts, and attributed their central role in start-up success to Malta's small size and high population density. Contacts, networking and word-of-mouth were considered to be important in replacing or complementing conventional forms of marketing or advertising:

I feel that, especially in a place like Malta, you can reach your customers in so many better ways besides advertising. We're only 350,000 people on this island, so if you have $10 \%$ of the market you can actually probably meet these $10 \%$ in the street. So you can do a lot of marketing which is one to one, personal and more targeted ... the best is always mouth to mouth. Word of mouth is the best, strongest thing.

These factors were also reportedly important in being awarded jobs and in attracting and retaining clients. Building and maintaining a good reputation was also a major issue in these cases as seen from the three quotes below from three different respondents:

I think it all boils down out here to who you know in most cases, in making big money out here ... There are people who wouldn't deal with anyone, but they deal with us ... they know we provide a proper service or whatever ... You have to build the right reputation ... but we have to be sure not to make mistakes, because you only make a mistake once with these people and they'll never come back. That's the way it works out here. So you've got to work hard to build a good reputation, and you have to work hard again to protect it.

Word of mouth is paramount on this island. I think the minute an organization has a reputation ... a reputation for what it does best, I think that is critical ... Already I find myself being awarded jobs ... merely on reputation.

The most important thing is reputation for us. It takes a long time to create it and it is very easy to lose it, even in - especially in - a small country like Malta. For example, if we provide a bad service, everybody will know because word will really go round very, very quickly. And unlike, say, if we were providing a service in Italy and you have a bad reputation in say, Milan, you can move to Torino. In Malta that is not possible. So reputation is fundamental for us to grow in a small island like Malta.

That familiarity could breed contempt was not far from the surface. A respondent highlighted the lack of cooperation between the Maltese as follows:

We have a 'dog eat dog' attitude here in Malta. I say this to everyone, it is our culture. Knocking on someone's door to ask for help is unheard of here. 
From Phase One of the research, only two respondents claimed that the legislative and procedural issues involved in starting up an enterprise in Malta are easy. The rest complained about the enterprise environment particularly about excessive bureaucracy and mandatory paperwork. These problems seem to be even more pronounced once the enterprise had been established and was up and running. One respondent explained that he would have liked to relocate to larger premises to enable him to expand, but he wasted seven months dealing with red tape and bureaucracy.

\section{RQ3: What are the key success factors among Maltese start-ups?}

In Phase Two of the research, telephone survey participants were asked to weigh each of twelve key success factors against creativity and innovation, and to indicate whether they believed that these factors were less important, equally important or more important than creativity and innovation in starting up their business. The response category was treated as a metric interval variable with less important being assigned the value of 1.00, equally important assigned the value of 2.00, and more important assigned the value of 3.00 . The mean of each of the twelve variables was calculated to obtain an indication of their overall relative importance. A mean between 2.00 and 3.00 indicates that the variable is more important than creativity and innovation, while a mean between 1.00 and 2.00 indicates that the variable is less important than creativity and innovation. This procedure used the mean score obtained to rank the factors according to their perceived relative importance. Table 1 presents the means and standard deviations for each variable ranked in descending order of overall relative importance. It indicates that the top three start-up success factors identified are 'reputation' $(M=2.62)$, 'contacts, networking and word of mouth' $(M=$ $2.61)$, and 'quality' $(M=2.58)$. Table 1 also indicates that nine factors were rated as more important than creativity and innovation, while three factors were rated as less important.

Table 1: Overall Relative Importance of Each Factor

\begin{tabular}{llc}
\hline & Mean & Std. Deviation \\
\hline Reputation & 2.62 & 0.53 \\
Contacts, networking and word of mouth & 2.61 & 0.59 \\
Quality & 2.58 & 0.58 \\
Staff & 2.44 & 0.69 \\
Cash flow & 2.42 & 0.73 \\
Education and experience & 2.30 & 0.74 \\
Marketing & 2.24 & 0.72 \\
Family support & 2.17 & 0.78 \\
Capital & 2.07 & 0.83 \\
Technology & 1.97 & 0.84 \\
Location & 1.47 & 0.75 \\
Professional advice & 1.44 & 0.67 \\
\hline
\end{tabular}




\section{Baldacchino, V. Cassar \& A. Caruana}

One should note that a number of factors have means which are very close to the mean of 2.00 and are therefore understood to be as important as creativity and innovation for startup success. Yet, the above provides no indication as to which are close enough to be considered as equally important to creativity and innovation, and which are distant enough to be considered as significantly more or significantly less important. One-variable chisquare tests were therefore carried out using the frequency counts of each variable to investigate which of the factors are significantly more / less important than creativity and innovation. No significant differences were found on 'family support', 'capital' and 'technology' $(N=90, d f=2, p>.05)$. These factors may therefore be considered to be of equal importance to creativity and innovation. Seven factors, namely 'reputation', 'contacts, networking and word of mouth', 'quality', 'staff', 'cash flow', 'education and experience', and 'marketing' were found to be significantly more important than creativity and innovation, while two factors, namely 'location' and 'professional advice', were found to be significantly less important than creativity and innovation $(N=90, d f=2, p<.05)$.

\section{RQ4: How are creativity and innovation reflected in Maltese start-ups?}

The majority of owner-managers who participated in Phase One of this research claim that creativity and innovation play a crucial role in the success of their start-up. When asked what the most important factors were in the success of their start-up, nine of the thirteen respondents made some reference to creativity and innovation. The subsequent probing by the interviewer elicited a great deal of information on this theme. Most owner-managers claimed that they are in some way creative and that their start-up is innovative as a function of their creativity. Sometimes they were able to specify ways in which they were creative and innovative; other times they were not. For example, one respondent described his "creative approach". He explained that he begins a new project "with a tabula rasa, a clean slate ... just get rid of all your rules, just throw everything out of the window and start afresh". On the other hand, another respondent stated that he thinks he is "a bit creative" but does not know "how or what". He thinks it must be "something to do with character". Another owner-manager claimed to have so many creative ideas that, were he to live another seven lifetimes, it would still not be enough for him to put them all into action. This same respondent explained that, when he puts these creative ideas into action, he often finds that his products are too advanced for the market.

This concern about products or services that were so innovative that the market was not yet ready for them was voiced by three other respondents. Six other respondents stated that they introduced products or services that were new to the Maltese market but which had been available abroad. For some, this innovation gave their start-up competitive advantage:

It was innovative for Malta ... that was our competitive advantage, that we harnessed technology ... That made us save a lot of money which was also an advantage to our customer.

Others voiced similar concerns regarding a market that was not ready for innovation: "it was new for Malta, but not for overseas ... and first we started to make the market aware of our products which sort of the Maltese market was not ready yet for them". Only one 
respondent admitted that his start-up simply offered "more of the same". Yet even he claimed to be "always trying to design new products ... always trying to create something new".

Creativity and innovation were deemed important for initial survival and for continued growth and success, with frequent references to initial innovative business ideas, a subsequent flow of new ideas for products or services, creative solutions to problems and innovative business processes. When asked about the main reason behind the success of his start-up, a respondent answered that he had: "the idea which is unique so that helped a lot". He also claimed that "the only way to keep ahead [of the competition] is to add new services, new ideas". Having an innovative business idea was also cited by another respondent as being an important factor in the success of her start-up. Another respondent claimed that an innovative product helped to "penetrate the market" with a high quality product with a considerable price tag attached. He believed this was only possible because customers knew their product was not a "me too" product but something very different, and it was one of the major reasons why his start-up was successful. Another respondent believes that the only way to succeed is to stand out by being unique, different and original. "Having new ideas is extremely important", he explained, "if you're going to be like everyone else, you're just going to fall in with the rest of the crowd". He believes that his "creative approach" ensures that his products are always innovative and that this is one of the major reasons why he has been so successful.

In spite of the importance of creativity and innovation, many owner-managers cautioned that other conditions must be present, both to enhance start-up success and to enable the start-up to innovate. Thus, one respondent warned that when he was younger he believed that having a good business idea is enough to guarantee success, but experience had taught him otherwise. He learned that without "business acumen" and a steady cash flow, ideas are useless. He spoke about business acumen as "a sort of toughness which is built up with years of experience", and compared the development of an entrepreneur as follows:

In business you are like a turtle. You are born without a protective shell, so each strike is painful and could kill you. As time goes by, your shell begins to get harder and tougher ... so, if you are struck you might flinch, but you would keep going...

There was also some scepticism about the importance of creativity and innovation in startup success, since there are other factors which were deemed more important. One respondent believed that innovative but unbranded products have a very difficult time competing with established brands, particularly those enjoying extensive marketing and which have built a name for themselves:

All I can say is that no matter how innovative I would be, and no matter how much money I would spend on local marketing on a product, if I had a competitor whose product was established and advertised on Canale 5 [an Italian TV station that can be viewed from Malta] then forget it! You can never ever compete, not even with the most innovative washing machine which hangs out your clothes to dry and irons them... 


\section{Baldacchino, V. Cassar \& A. Caruana}

This respondent believes that truly innovative products require huge amounts of financial backing in order to become commercially viable, which was not easy for a start-up to obtain. He spoke about an experience he had with a previous start-up, where he came up with an idea for a radically innovative product. When he attempted to launch this product, he found out he did not have the financial resources to follow through, and sold the concept to a larger company. His buyer could afford to inject the required capital to launch this product on the international market where it turned out to be a huge success.

Financial factors were mentioned as major start-up concerns by another seven respondents during the personal interviews. The owner-managers in this phase of the study were aware that starting up and running an enterprise requires a substantial amount of money, and that surviving and succeeding requires adequate initial and continued funding. Two comments from two different respondents were: "[f]irst of all, you need good financial back-up"; and "I wouldn't advise anyone to start a new business without having a proper budget". Respondents complained about the lack of financing available to start-ups in Malta, where the banks always require collateral for a loan and where venture capitalists and business angels are almost non-existent.

Nevertheless, being a small enterprise was often regarded as advantageous by these ownermanagers, especially in terms of added flexibility and faster reaction times. One respondent believes that an entrepreneur has to be a "... sort of a chameleon, to be able to change colour and change attitude, to change according to whom you are dealing with", which according to two other respondents is facilitated by the small size of their start-up.

A final factor from the qualitative section of the research that is seen as central to start-up success is the enthusiasm and passion with which the owner-managers in Phase One of this study spoke about their start-ups. This was evident in the respondents' non-verbal communication - the look in their eyes, the tone of their voice, and the eagerness with which they spoke about their start-ups all pointed towards a source of great pride and satisfaction. Three respondents even spoke about their start-up as if it were a baby that required their nurturing, care and attention. For example, one respondent commented that "the start-up period is a very fragile period, it's a baby that's not grown as yet". This intense emotional involvement may be considered to be crucial to these owner-managers.

The results from the qualitative research in Phase One were enhanced with the quantitative research in Phase Two. This involved the computation of frequency counts and percentages for each of the items in part two of the telephone interview. Since these variables represent indicators of creativity and innovation, the statistics provide a general indication of how creativity and innovation are reflected in Maltese start-ups and provide further depth in understanding how creativity and innovation are reflected in Maltese startups.

Well over half the owner-mangers in this study reported having launched products or services that were new to the Maltese market, while just over a quarter of these products or services were also new to the international market. This adds up to $16.7 \%(n=15)$ of the total sample launching products or services that were brand new at the time of start-up. The 
majority $(89.5 \%)$ of these owner-managers reported that their new-to-market products or services had been a success. Most owner-managers $(71.1 \%, n=64)$ reported that, as time passed, they added new products or services to their range, made improvements to existing products or services, and upgraded methods of production or delivery, all of which are indicators of product, service or process innovation.

The majority of start-ups in this study reportedly enjoy extensive generation and implementation of new ideas, both by the owner-managers and by employees. A considerable $94.4 \%(n=85)$ of owner-managers personally generate and develop ideas for their start-ups, and $83.3 \%(n=75)$ also encourage employees to come up with new ideas. Only two respondents had never implemented ideas proposed by their employees. Furthermore, only three of the owner-managers who did implement employees' ideas had witnessed no improvement in some aspect of their start-up.

The owner-managers commented on the effort required to be alert and be prepared to react to changes in their surroundings, with $96.7 \%(n=87)$ reporting that they keep abreast with emerging trends and technologies, and $90 \%(n=81)$ claiming that their start-up is quick to adapt to changes in customer requirements or competition as well as to other changes in their environment.

\section{Discussion}

The personal interviews that focused on conditions accentuated by Malta's small island state context support the body of literature which argues that Malta has a particular microenvironment made up of its physical, social, cultural and economic characteristics (Baldacchino, 1995; Sultana, 2006). The findings of this study strongly indicate that this micro-environment is highly influential on start-up activities and their chances of success. Respondents in this study held contrasting views on whether Malta's size and physical location enhance or inhibit start-up success. This study therefore reflected the dualism that exists in the literature in this regard. Maltese culture has been found to be receptive to new ideas supporting the link between openness to new ideas and survival in a country lacking natural resources. Interestingly, and perhaps somewhat contradictorily, Maltese culture was also described as being anti-entrepreneurial due to rampant piracy of ideas. This practice could be mitigated and entrepreneurship supported by improving intellectual property rights that protect those groups or individuals who generate ideas for innovative products, services or processes.

During the personal interviews, several owner-managers reported that their family was in some way influential in their decision to start up their enterprise. Others spoke of the invaluable moral, practical and financial support they receive from spouses. These respondents support the central role of the family in the Maltese start-up process. Although it could be argued that such a practice applies internationally, the strong family values that are still present in Maltese society, and the physical proximity that is retained to the family of origin even after marriage, could explain their added importance in Malta. However, despite being discussed at length during the personal interviews, family support was not rated as highly as might be expected by respondents during the telephone interviews. This 


\section{Baldacchino, V. Cassar \& A. Caruana}

could be due to the reflective nature of family-related issues which are more suited to qualitative research, where they can be discussed in depth and at length.

Respondents in both phases of this study reported that the interrelated issues of reputation, contacts, networking and word-of-mouth are crucial to start-up success, as they replace or complement traditional forms of marketing and help attract and retain customers. Only one respondent lamented that cooperation was sorely lacking among the Maltese. All the other respondents agreed that the success of their start-ups depends to a large extent on their contacts, networking activities and word-of-mouth. This confirms that Boissevain's (1974) "friends of friends" phenomenon is still very much alive in Malta. The physical proximity and familiarity that characterize Maltese society offer added opportunities for direct human interaction, which facilitates networking activities and adds value to personal contacts in start-up success. The equally high importance attributed to building and maintaining a good reputation in Malta is most likely due to the same reasons. Reputation is a valuable asset in any part of the world, but when one lives on a small, densely populated island where much activity takes place in the public eye and where news travels fast, both successes and failures become quickly known. Relocation to start again can only be to another country as it becomes impossible to operate in a hostile business environment with shattered networks and broken relationships.

The personal interviews indicate that creativity and innovation are critical to start-up success, as the majority of owner-managers reported that one of the major factors in their success was that they were in some way creative and innovative. Initial survival, sustained growth and competitiveness were reportedly enhanced by creative business ideas and innovative products, services and processes. This supports the vast body of literature which claims that creativity and innovation are indispensable for business success (e.g., Kuczmarski, 1996; Parks, 2006; Peña, 2002; Witt, 2004). However, the telephone interviews conducted during the second phase of the study identified seven other factors that were deemed to be more important than creativity and innovation. At face value this may suggest that creativity and innovation are not as critical as they initially appeared to be. However one must bear in mind that all twelve factors that respondents were asked to weigh against creativity and innovation are, according to the literature review and findings of the first phase of this study, all fundamental to start-up success. Therefore these results should not be interpreted as a sign that creativity and innovation are not critical to success. On the contrary, the fact that creativity and innovation were rated to be of equal or greater importance than five of the factors on the list implies that they are indeed among the key success factors of Maltese start-ups, and that they therefore have a central role to play in the growth and prosperity of local enterprises. However, these findings confirm that creativity and innovation alone are insufficient for start-up success.

Financial and marketing issues have been identified as major concerns among respondents with initial capital being seen as less important than a steady cash flow. Most of the startups in this study are knowledge-based enterprises and therefore did not require hefty initial investments to purchase large premises and expensive machinery. However, once these enterprises began operating, running costs quickly increased. Unless the initial start-up capital is large enough, a steady cash flow becomes crucial to ensure survival and success. 
Marketing issues and the provision of products or services of a high quality were also rated as significantly more important than creativity and innovation in this study. A likely reason for these findings is that, although offering innovative products is important, these products must be marketed and must be of high quality to ensure customer satisfaction.

Findings from both phases of this study indicate that Maltese start-ups display high levels of creativity and innovation. The personal interviews provided various examples of how the owner-managers in this study employ their creative thinking skills to compensate for shortcomings, overcome obstacles and create opportunities in their start-ups. The telephone interviews suggest that nearly all owner-managers claim to generate, develop and implement new ideas for their start-ups. Together, these findings offer substantial support for the literature that argues that creativity is central to and inseparable from the entrepreneurial process (Barringer \& Ireland, 2006), and confirm that creative thinking is an essential entrepreneurial skill (Pretorius et al., 2005).

\section{Limitations and Directions for Future Research}

Although this study was designed to address the research questions as closely and accurately as possible, the research design and methodologies gave rise to a number of inherent limitations which could not be eliminated. Other limitations arose at a later stage of the study from circumstances that were beyond the researchers' control. The fact that the research sample was made up exclusively of owner-managers raised the possibility of biased responses where indicators of creativity and innovation were concerned. The respondents may have refrained from providing information which they felt would reflect negatively on themselves or their start-up. One should bear in mind that many ownermanagers take great pride in their start-up, and some even refer to it as if it were their child. It is likely that, just as a parent would want to mask his/her child's shortcomings to strangers, owner-managers would be reluctant to admit the deficiencies of their start-up to third parties. Thus there is a possibility that they provided responses that they believed were socially desirable. There is also a likelihood that they replied truthfully, but their perception of the situation was somewhat distorted and biased. This would mean that they inadvertently provided misguided views of their start-ups' indicators of creativity and innovation.

One way to compensate for this limitation would have been to use triangulation, obtaining the views of employees and to personally visit the start-ups for direct observation. This would have been too time-consuming, excessively invasive and disruptive for the start-ups involved and was therefore avoided. One should also consider that it is unlikely that employees would be in a position to provide information regarding start-up success factors. The lifeblood of a start-up runs through the veins of its owner-manager: no one else is better equipped to divulge which factors contributed to business success. Nevertheless, it would be beneficial for future research into creativity and innovation in start-ups to include triangulation of methods to obtain a holistic picture and reduce as much as possible that bias resulting from perceptual data that is bound to influence results. 


\section{Baldacchino, V. Cassar \& A. Caruana}

On a positive note, the use of purposive sampling ensured the selection of a theoretically relevant sample, which is highly recommended for entrepreneurial research (Davidsson, 2004). Thus although the small sample size does not allow confident generalisations to the population of start-up owner-managers in Malta, the sampling method used ensures that the enterprises under investigation were all perfectly suited for the purpose of this research. This in turn increased the validity of the findings that are largely in line with the relevant literature.

Another limitation of this study was the absence of a comparison group in the form of owner-managers whose start-ups had not survived. This would have permitted comparisons between survivors and non-survivors, and would have added insight into the factors that play a critical role in the success of start-ups in Malta's small island state context. Future research could investigate similarities and differences between successful and unsuccessful start-ups. It would be interesting to see whether failed start-ups were any less creative and innovative than successful ones, and whether this has any bearing on the outcome of their business endeavours.

\section{References}

Abraham, J. \& Knight, D. (2001) 'Strategic Innovation: Leveraging Creative Action for More Profitable Growth', Strategy and Leadership, Vol. 29, No. 1, pp. 21-26.

Advanced Practical Thinking Training Inc. (2001) Innovation Index, http://www.aptt.com/innovationindex.htm.

Amabile, T.M., Conti, R., Coon, H., Lazenby, J. \& Herron, M. (1996) 'Assessing the Work Environment for Creativity’, The Academy of Management Journal, Vol. 39, No. 5, pp. 1154-1184.

Baldacchino, G. (1995) 'Labour Formation in Small Developing States: A Conceptual Review’, Compare, Vol. 25, No. 3, pp. 275-278.

Baldacchino, G. (1999) 'Small is Back: A Manifesto - The Very Characteristics Which Are Believed to Signify Vulnerability of Small Island States May Well Be Interpreted as Signs of Strength', The Journal of Nordregio, Vol. 10, No. 2/3, pp. 21-26.

Baldacchino, G. (2002) 'A Taste of Small Island Success: A Case from Prince Edward Island', Journal of Small Business Management, Vol. 40, No. 3, pp. 254-259.

Barringer, B.R. \& Ireland, R.D. (2006) Entrepreneurship: Successfully Launching New Ventures, New Jersey, Pearson Prentice Hall.

Boissevain, J. (1974) Friends of Friends: Networks, Manipulators and Coalitions, New York, St. Martin's Press. 
Boissevain, J. (1991) 'Small Entrepreneurs and their Cultural Context', Bank of Valletta Review (Malta), No. 3, pp. 1-16.

Boissevain, J. (1993) Saints and Fireworks: Religion and Politics in Rural Malta, Malta, Progress Press.

Bosma, N. \& Harding, R. (2007) Global Entrepreneurship Monitor: GEM 2006 Results. Babson College MA and London, London Business School.

Briguglio, L. \& Kisanga, E. J. (eds.) (2004) The Economic Vulnerability and Resilience of Small States, Commonwealth Secretariat.

Cook, P. (1998) 'The Creativity Advantage - Is Your Organisation the Leader of the Pack?', Industrial and Commercial Training, Vol. 30, No. 5, pp. 179-184.

Creswell, J. (1998) Qualitative Inquiry and Research Design: Choosing among Five Traditions, Thousand Oaks, Sage.

Cummings (2005a) 'Open Systems' in N. Nicholson, P. Audia \& M. Pillutla (eds.) The Blackwell Encyclopedia of Management (Vol. XI: Organizational Behavior), Oxford, Blackwell Publishing Ltd., pp. 255-256.

Cummings (2005b) 'Systems Theory' in N. Nicholson, P. Audia \& M. Pillutla (eds.) The Blackwell Encyclopedia of Management (Vol. XI: Organizational Behavior), Oxford, Blackwell Publishing Ltd., pp. 384-386.

Dana, L.P. (2006) Entrepreneurship and SMEs in the Euro-Zone: Towards a Theory of Symbiotic Entrepreneurship, London, Imperial College Press.

Davidsson, P. (2004) Researching Entrepreneurship, New York, Springer.

Dickson, K. \& Hadjimanolis, A. (1998) 'Innovation and Networking among Small Manufacturing Firms in Cyprus', International Journal of Entrepreneurial Behaviour and Research, Vol. 4, No. 1, pp. 5-7.

Dodge, H. R. \& Robbins, J. E. (1992) 'An Empirical Investigation of the Organizational Life Cycle Model for Small Business Development and Survival', Journal of Small Business Management, January, pp. 27-37.

Ekvall, G. (1987) Creative Climate Questionnaire. Reproduced with permission by the Center for Studies in Creativity at the State University College at Buffalo, New York.

Frankfort-Nachmias, C. \& Nachmias, D. (1996) Research Methods in the Social Sciences, London, Arnold.

Friedman, T. (2005) The World is Flat, NY, Farrar, Straus and Giroux. 
Gilmore, A., Carson, D. \& O’Donnell, A. (2004) 'Small Business Owner-Managers and their Attitudes to Risk', Marketing Intelligence and Planning, Vol. 22, No. 3, pp. 349-360.

Goodman, M. (1995) Creative Management, London, Prentice Hall.

Gurteen, D. (1998) 'Knowledge, Creativity and Innovation', Journal of Knowledge Management, Vol. 2, No. 1, pp. 5 -13.

Harvard Business Essentials (2003) Managing Creativity and Innovation, Boston MA, Harvard Business School Publishing Corporation.

Helms, M. \& Renfrow, T. (1994) 'Expansionary Processes of Small Business: A Life Cycle Profile', Management Decision, Vol. 32, No. 9, pp. 43-45.

Heye, D. (2006) 'Creativity and Innovation: Two Key Characteristics of the $21^{\text {st }}$ Century Information Professional', Business Information Review, Vol. 23, No. 4, pp. 252-257.

Hill, J., Nancarrow, C. \& Wright, L.T. (2002) 'Lifecycles and Crisis Points in SMEs: A Case Approach', Market Intelligence and Planning, Vol. 20, No. 6, pp. 361-369.

Kuczmarski, T. (1996) 'What is Innovation? The Art of Welcoming Risk', Journal of Consumer Marketing, Vol. 13, No. 5, pp. 7-11.

Lee, S.S. \& Osteryoung, J. S. (2001) 'A Comparison of Determinants for Business Startup in the U.S. and Korea', Journal of Small Business Management, Vol. 39, No. 2, pp. 193-200.

Loewe, P. \& Dominiquini, J. (2006) 'Overcoming the Barriers to Effective Innovation', Strategy and Leadership, Vol. 34, No. 1, pp. 24-31.

Luger, M. \& Koo, J. (2005) 'Defining and Tracking Business Start-ups', Small Business Economics, No. 24, pp. 17-28.

Lundström, A. \& Stevenson, L. (2005) Entrepreneurship Policy: Theory and Practice, NY, Springer Science and Business Media.

Lussier, R. \& Pfeifer, S. (2001) 'A Crossnational Prediction Model for Business Success', Journal of Small Business Management, Vol. 39, No. 3, pp. 228-239.

Martins, E.C. \& Terblanche, F. (2003) 'Building Organizational Culture that Stimulates Creativity and Innovation', European Journal of Innovation Management, Vol. 6, No. 1, pp. 67-74.

McGrath, M. \& Gilmore, D. (1995) 'Achieving Growth, Competitive Advantage and Increased Profits', World Class Design to Manufacture, Vol. 2, No. 6, pp. 11-16. 
Mehmet, A. \& Tahiroglu, M. (2002) 'Growth and Equity in Microstates: Does Size Matter in Development?', International Journal of Social Economics, Vol. 29, Nos. 1/2, pp. 152162.

Mercieca, K. \& Cassar, V. (2006) 'Profiling the Maltese Entrepreneur? A Model and Preliminary Findings', paper presented at Conference on Successful Small Business from Small Islands, San Gwann, Malta, Malta Enterprise.

Moy, J. \& Luk, V. (2003) 'The Life Cycle Model as a Framework for Understanding Barriers to SME Growth in Hong Kong', Asia Pacific Business Review, Vol. 10, No. 2, pp. 199-220.

National Statistics Office Malta (2006a) A Review of Medium and Large Enterprises. www.nso.gov.mt/statdoc/document_view.aspx?id=1779.

National Statistics Office Malta (2006b) A review of Micro and Small Enterprises: 2002 2004, www.nso.gov.mt/statdoc/document view.aspx?id=1663.

Parks, S. (2006) How to be an Entrepreneur: The Six Secrets of Self-made Success, London, Prentice Hall.

Peña, I. (2002) 'Intellectual Capital and Business Start-up Success', Journal of Intellectual Capital, Vol. 3, No. 2, pp. 180-198.

Pretorius, M., Millard, S. M. \& Kuger, M. E. (2005) 'Creativity, Innovation and Implementation: Management Experience, Venture Size, Life Cycle Stage, Race and Gender as Moderators', South African Journal of Business Management, Vo. 36, No. 4, pp. 55-68.

Shaughnessy, J. \& Zechmeister, E. (1997) Research Methods in Psychology, New York, McGraw Hill.

Schutjens, V. \& Wever, E. (2000) 'Determinants of New Firm Success', Papers in Regional Science, Vol. 79, No. 2, pp. 135-159.

Simpson, M., Tuck, N. \& Bellamy, S. (2004) 'Small Business Success Factors: The Role of Education and Training', Education and Training, Vol. 46, Nos. 8/9, pp. 481-491.

Smallbone, D., Leigh, R. \& North, D. (1995) 'The Characteristics and Strategies of High Growth SMEs', International Journal of Entrepreneurial Behaviour and Research, Vol. 1, No. 3, pp. 44-62.

Sternberg, R. \& Wennekers, S. (2005) 'Determinants and Effects of New Business Creation using Global Entrepreneurship Monitor Data', Small Business Economics, No. 24, pp. 193-203. 
Sultana, R.G. (2006) Challenges for Career Guidance in Small States, Malta, EuroMediterranean Centre for Educational Research.

Waters, L., McCabe, M., Kiellerup, D. \& Kiellerup, S. (2002) 'The Role of Formal Mentoring on Business Success and Self-esteem in Participants of a New Business Startup Program', Journal of Business and Psychology, Vol. 17, No. 1, pp. 107-121.

Watson, K., Hogarth-Scott, S. \& Wilson, N. (1998) 'Small Business Start-ups: Success Factors and Support Implications', International Journal of Entrepreneurial Behaviour and Research, Vol. 4, No. 3, pp. 217-238.

Witt, P. (2004) 'Entrepreneurs' Networks and the Success of Start-ups', Entrepreneurship and Regional Development, Vol. 16, No. 4, pp. 391-412.

World Economic Forum (2006a) The Lisbon Review 2006: Measuring Europe's Progress in Reform, Geneva, www.weforum.org/en/initiatives/gcp/Lisbon\%20Review/index.htm.

World Economic Forum (2006b) Global Competitiveness Report 2006, Geneva, www.weforum.org/en/initiatives/gcp/Global\%20Competitiveness \%20Report/index.htm. 